\title{
Equity Market Integration of New EU Member States
}

\author{
Lorenzo Cappiello, Bruno Gérard, Arjan Kadareja and Simone Manganelli *†
}

December 2005

\begin{abstract}
This study assesses the degree of equity market integration for a selected number of new EU member states among themselves and with the euro zone. Within the framework of a factor model for market returns, we adopt an intuitive measure of integration: the higher the amount of return variance explained by the global factor relative to the local components, the higher the degree of integration. Next we derive a relationship between return correlation and the measure of integration. Equity market integration is measured with a regression quantilebased methodology. Evidence suggests that for Czech Republic, Hungary and Poland the degree of integration has increased significantly over the last few years. This is not the case for Cyprus, Estonia, Latvia and Slovenia.
\end{abstract}

Keywords: Integration, new EU member states, regression quantile

JEL classification: C32, F30, G12

\footnotetext{
*Cappiello, Kadareja and Manganelli are with DG Research, European Central Bank, Kaiserstrasse 29, 60311 Frankfurt am Main, Germany. Email: lorenzo.cappiello@ecb.int, arjan.kadareja@ecb.int, and simone.manganelli@ecb.int; tel.: +49 691344 8765, +49 6913447015 , +49 691344 7347, respectively. Gérard is with Mellon Capital Management, 595 Market Street Suite 3000, San Francisco, CA 94105, email: brunog@mcm.com, tel.: 1-415-975 3569. Most of the work was completed while Gerard was with the department of Finance and CentER, Tilburg University, and with the Norwegian School of Management BI, Oslo, Norway.

${ }^{\dagger}$ We are indebted to Lieven Baele, Vítor Gaspar, as well as participants at the European Central Bank seminar, the Conference on Financial Integration in Europe and the Propagation of Shocks (DIW, Berlin), the Conference on European Economic Integration (OeNB, Vienna) for their valuable comments and discussions. The usual disclaimer applies. The views expressed in this paper are those of the authors and do not necessarily reflect those of the European Central Bank, the Eurosystem or Mellon Capital Management.
} 


\section{Introduction}

The extent to which international goods and financial markets are integrated is an issue of continuing interest for policymakers and market participants, whether firms, investors, or financial intermediaries. On the one hand, a high degree of economic and financial integration is beneficial since it can foster economic growth, increasing risk sharing and allocating savings more efficiently. On the other hand, however, it may also lead to high cross border economic interdependence and transmission of shocks.

The goal of this paper is to assess the degree of economic and financial integration of a selected number of new EU member states. There is no unanimous definition of integration in the literature. In financial economics (see, for example, Adler and Dumas, 1983, Stulz, 1981, and Flood and Rose, 2005), markets are said to be integrated when only common risk factors are priced and (partially) segmented when local risk factors also determine equilibrium returns. Another, more general definition relates market and economic integration to a strengthening of the financial and real linkages between economies (see, inter alia, Dumas, Harvey and Ruiz, 2003). Typically, estimates of the first definition of integration require sophisticated asset pricing tests (examples are given by Bekaert and Harvey, 1995 and 1997, and Rockinger and Urga, 2001). Estimates of the second, instead, are usually conducted by investigating the changes in the comovements across countries between selected financial asset returns (see, for instance, Dumas, Harvey and Ruiz, 2003, and Aydemir, 2004). In this paper we focus on the second type of tests.

We study integration between new EU member states and the euro zone across two different periods: the pre-convergence and the convergence periods. Since the new EU member states will eventually join the European monetary union, it is important to monitor the development of the economic and financial links between these countries and the euro zone.

We employ a factor model for market returns which distinguishes between global and local components. Since economic fundamentals are reflected in financial market prices, factor models represent a natural tool to investigate to which extent these fundamentals have been converging over time. Although we express market returns in terms of a factor model, we do not estimate the model itself nor its factor loadings. 
This constitutes an adavantage, since it shelters our approach from a joint hypothesis critique: if integration were rejected, this could be due to truly segmented markets or to the misspecification of the factor model. Given the generality of the factor model we employ, rejection of integration must be due to market segmentation rather than incorrect model specification or estimation.

The simple model we consider allows us to adopt an intuitive measure of integration: the higher the amount of return variance explained by the global factor relative to the local components, the higher the degree of integration. Next, we derive a precise relationship between return correlation and the measure of integration: if the correlation between two markets increases, the integration indicator should rise as well.

Return co-dependences are estimated with the "comovement box" methodology introduced by Cappiello, Gérard and Manganelli (2005). This approach possesses, inter alia, two advantages. First, contrary to standard correlation measures, it is robust to time varying volatility and departure from normality. Second, it offers a simple and intuitive visual measure of integration. The comovement box methodology provides a long term average of the co-dependence between any two financial market returns across two distinct subperiods.

Most empirical studies investigating integration have focused on developed markets (see, for instance, Jorion and Schwartz, 1986; Korajczyk and Viallet, 1989; Campbell and Hamao, 1992, Bekaert and Harvey, 1995; Carrieri, Errunza and Sarkissian, 2004; Baele et al., 2004; and Flood and Rose, 2005), while some recent papers have focused on emerging markets (e.g. Bekaert and Urias, 1996; Bekaert and Harvey, 1997; Bekaert et al. 1998; Bekaert, 1999; Bekaert and Harvey, 2000; Rockinger and Urga, 2001; Gérard, Thanyalapark and Batten, 2003). However, no study has exclusively analysed the new EU member states, despite their unique characteristics. On the real economy side, these countries went from centrally planned-, to market-, to fully open-economies, becoming members of a free trade area within the very short time span of 12 years. In parallel, these economies had to evolve through a very quick development and liberalization of their financial markets. Lastly, all these countries went through these changes at a roughly similar pace. 
We carry out our analysis on returns on equity market indices. Evidence suggests that the degree of integration of the new EU member states with the euro zone (and in particular with Germany, which we chose as a benchmark for the euro area) has increased in their process towards EU accession. We find that, for the three new EU member states with the largest economies and most developed financial markets, Czech Republic, Hungary and Poland, return comovements between themselves and with Germany increase significantly over the sample period. For the four smaller countries, Cyprus, Estonia, Latvia and Slovenia, we document that the degree of comovements remains low and/or unchanged throughout the sample. This suggests that although all these countries have experienced tremendous development in their financial markets, they exhibit different degrees of integration and different speed of convergence with the euro zone.

The paper is structured as follows. Section 2 provides a brief literature review that leads us to motivate the use of a particular integration indicator. We also derive a relationship between this indicator and correlation measures. In section 3 , we explain the empirical methodology. Section 4 contains a brief description of the data and main developments in new EU member state equity markets. In section 5 we discuss the empirical results, while section 6 concludes.

\section{Measuring integration}

Consider first a closed economy with an efficient local financial market. In such an economy, firms' cash flows and equity returns depend on local factors only. Consider, in contrast, fully open economies, without barriers to trade and financial transactions. In such a world local firms' equity returns are a function of not only domestic but also foreign factors. As a consequence, when a country moves from being closed to an open status, the impact of global factors on domestic firms' cash flows should increase. Therefore the transition to an open economy regime should be accompanied by an increase in comovements in equity prices.

Against this background, we express asset returns in a national market, $r_{i t}$, in terms of a global factor and a number of local factors. Next, we adopt as a measure 
of integration the share of variance explained by the common factor. In general the higher this share, the higher the degree of integration. If markets are perfectly segmented the variance explained by the global factor is equal to zero. On the other hand, if markets are perfectly integrated, all the local factor loadings will be equal to zero and most of the variation will come from the global factor. ${ }^{1}$

It is possible to show that there is a precise relationship between standard correlation measures and our integration indicator. In particular, correlation is proportional to the amount of the total variance explained by the global component. If two markets, $i$ and $j$, are integrated, the correlation between returns on an asset in market $i$ and $j$ will increase.

\section{The empirical approach}

We evaluate correlations adopting the "comovement box" framework developed by Cappiello, Gérard and Manganelli (2005).

Tests for changes in comovements are usually conducted by correlations estimates. However these tests are sensitive to heteroskedasticity (see, for instance, Forbes and Rigobon, 2002) and departure from normality. Therefore, a simple comparison between correlations over time could lead to spurious results. The comovement box methodology, instead, is robust to time varying volatility and departure from normality.

Let $\left\{r_{i t}\right\}_{t=1}^{T}$ and $\left\{r_{j t}\right\}_{t=1}^{T}$ denote the time series returns of two different markets. Let $q_{\theta t}^{r_{i}}$ be the time $t \theta$-quantile of the conditional distribution of $r_{i t}$. Analogously, for $r_{j t}$, we define $q_{\theta t}^{r_{j}}$. For each quantile $\theta$, we estimate a conditional probability $p_{t}(\theta)$ that, at time $t$, the returns on market $i$ are below (or above) its $\theta$-quantile, conditional on the same event occurring in market $j$.

The characteristics of $p_{t}(\theta)$ can be conveniently analysed in what we call the

\footnotetext{
${ }^{1}$ Bekaert and harvey, 1997, investigate the the impact of world factors on emerging market country returns by considering (amongst others) the proportion of the country returns variance due to world factors. The main difference between our approach and theirs is that while Bekaert and Harvey use a switching regime $\mathrm{GARCH}$ model to estimate variances and covariances, we use a non-parametric approach to estimate co-movements directly.
} 
comovement box (see Figure 1). The comovement box is a square with unit side, where $p_{t}(\theta)$ is plotted against $\theta$. The shape of $p_{t}(\theta)$ will generally depend on the characteristics of the joint distribution of the time series returns $r_{i t}$ and $r_{j t}$, and therefore for generic distributions it can be derived only by numerical simulation. There are, however, three important special cases that do not require any simulation: 1) perfect positive correlation, 2) independence and 3) perfect negative correlation. If two markets are independent, which implies $\rho_{i j t}=0 \forall t, p_{t}(\theta)$ will be piece-wise linear, with slope equal to one, for $\theta \in(0,0.5)$, and slope equal to minus one, for $\theta \in(0.5,1)$. When there is perfect positive correlation between $r_{i t}$ and $r_{j t}$ (i.e. $\rho_{i j t}=1 \forall t$ ), $p_{t}(\theta)$ is a flat line that takes on unit value. Under this scenario, the two markets essentially reduce to one. The polar case occurs for perfect negative correlation, i.e. $\rho_{i j t}=-1$ $\forall t$. In this case $p_{t}(\theta)$ is always equal to zero: when the realization of $r_{j t}$ is in the lower tail of its distribution, the realization of $r_{i t}$ is always in the upper tail of its own distribution and conversely (for a more formal description of the model see Cappiello, Gérard and Manganelli, 2005).

This discussion suggests that the shape of $p_{t}(\theta)$ provides key insights about the dependence between two asset returns $r_{i t}$ and $r_{j t}$. In general, the higher $p_{t}(\theta)$ the higher the codependence between the two time series returns.

While the conditional probabilities of comovements can be used to measure the dependence between different markets, the interest of the researcher often lies in testing whether this dependence has changed over time. Market integration is an important case in point. It is possible to test for changes in integration by evaluating if the conditional probability of comovements between two markets increases, for instance, after institutional changes. In the present application we estimate $p_{t}(\theta)$ over two different periods. When the conditional probabilities for these two different periods are plotted in the same graph, differences in the intensity of comovements can be identified directly. In particular, an upward (downward) shift of these curves would be consistent with an increase (decrease) of integration.

The framework of the comovement box can be used to formalize this intuition. Let $p^{B}(\theta) \equiv B^{-1} \sum_{t<\tau} p_{t}(\theta)$ and $p^{A}(\theta) \equiv A^{-1} \sum_{t \geq \tau} p_{t}(\theta)$, where $B$ and $A$ denote the number of observations before and after a certain threshold date $\tau$, respectively. We 
adopt the following working definition of increased integration:

Definition 1 (Integration) - Integration increases if $\delta(0,1)=\int_{0}^{1}\left[p^{A}(\theta)-p^{B}(\theta)\right] d \theta>$ 0 .

$\delta(0,1)$ measures the area between the average conditional probabilities $p^{A}(\theta)$ and $p^{B}(\theta)$.

Constructing the comovement box and testing for differences in the probability of comovement requires several steps. First, we estimate the univariate time varying quantiles associated to the return series of interest, using the Conditional Autoregressive Value at Risk (CAViaR) model developed by Engle and Manganelli (2004). Second, we construct, for each series and for each quantile, indicator functions which are equal to one if the observed return is lower than this quantile and zero otherwise. Finally, we regress the $\theta$-quantile indicator variable of returns on market $j$ on the $\theta$-quantile indicator variable of returns on market $i$, interacted with time dummies which identify periods of greater integration. These regression coefficients will provide a direct estimate of the conditional probabilities of comovements and of their changes across regimes.

\section{Data}

The empirical analysis is carried out on returns on equity market indices. All returns are denominated in local currencies. Equity indices include Germany, which constitutes our euro area benchmark, and a selected number of new EU member states, Cyprus, Czech Republic, Estonia, Hungary, Latvia, Poland and Slovenia.

Stock exchanges for the countries under consideration are approximately open over the same hours during the day, virtually ruling out any non synchronous effect. Nevertheless, asynchronicity may arise because there are instances in which markets are closed in one country and open in another, as national holidays and administrative closure do not fully coincide. To adjust for these non-simultaneous closures, we include only the returns for the days on which the markets under analysis were open that day and had been open the day before. Hence the daily returns we investigate are 
synchronous, avoiding the confounding effects that non synchronous returns can have on the measurement of integration.

Equity returns are continuously compounded and computed from Global Financial Data indices, which are market-value-weighted and include dividends. The daily data set covers the period from January 12th 1993 to August 2nd 1998 and from January 2nd 2001 to November 12th, 2004. We exclude data from August 1998 to December 2000 since the Russian crisis and the stock market bubble burst may induce spurious results.

\subsection{Developments in equity markets}

Equity markets of new EU member states developed along two different lines. Czech Republic adopted mass privatization schemes, whereas Estonia, Hungary, Latvia, Poland and Slovenia first established a legal framework for trading and next listed the enterprises. By and large, the second approach yielded better outcomes, as the first one resulted in a loss of confidence caused by the delisting of unsuccessfull companies (see Caviglia, Krause and Thimann, 2002).

The importance of the stock exchanges can be measured by the market capitalization as a percentage of GDP. At the end of 2001, Central European countries and Estonia had a stock market capitalization equal to 20-30\% of GDP, whereas Cyprus about $70 \%$, and the remaining countries less than $10 \%$. With the exception of Cyprus, these percentages are well below the euro area levels: at the end of 2001 the stock market capitalization for Germany was approximately equal to $60 \%$ of its GDP. In our sample, the three largest stock markets are Poland, Czech Republic and Hungary. Their relative stock market capitalization approximately reflects the respective countries' GDP weight in the region.

\section{Empirical Results}

We compute the probabilities of comovements over two sample periods. For equities we distinguish between a pre-convergence (before July 1998) and a convergence period (after January 2001). An increase in integration in the second period would be reflected by an upward shift in the probability of comovements. 
Figure 2 shows the GDP-weighted averages of the estimated comovement probabilities between new EU member states and Germany over the two sub-samples under consideration. In figure $2 \mathrm{a}$, which plots the probability averages relative to all countries, we observe an increase in the probability of comovements during the convergence period. This is consistent with an increase in the degree of integration. Interestingly, before 1998 these markets were virtually independent vis-à-vis Germany, probably because they were relatively new and had weak economic and financial ties with Western Europe and Germany in particular.

Figures $2 \mathrm{~b}$ and $2 \mathrm{c}$ present the breakdown of these average comovements by the economic size of the new member states. Most of the increase in comovements is mainly driven by the large new member states (Czech Republic, Hungary, and Poland) which make $85 \%$ of the total GDP in the region. Small new member states, instead, remain independent versus Germany also in the convergence period. This could be explained by institutional factors, the sheer size of the economy, the geographical distance and weak economic linkages with Germany.

These results are confirmed by country-pair analyses, which include $95 \%$ confidence bands. As an illustration, figure 3 plots estimated probabilities of comovements for Czech Republic vis-à-vis Germany across the two sub-samples.

Qualitatively similar conclusions can be inferred from Figure 4, where we analyse the probabilities of comovements among new member states. Figure 4a is supportive of an overall increase in the degree of integration. As before, most of it is due to the increase in comovements of large new member states, while small countries remain virtually independent even during the convergence period. The probabilities of comovements before and during the convergence period for the large countries are much higher than the corresponding probabilities which we observe when comparing Germany versus large new EU member states (see Figure 2b). The relatively high probabilities of comovements during the pre-convergence period may be explained by economic linkages which go back to the communist era. Country pair analyses once again confirm this outcome. It is particularly striking the case of Hungary and Poland (Figure 5), which suggests a high degree of integration between these two economies.

Formal tests, not reported here, of whether the level of comovements change sig- 
nificantly between pre- and convergence periods broadly confirm the graphical results.

\section{Summary of results and conclusions}

In this paper we evaluate the degree of integration between a selected number of new EU member states and with the euro zone. The analysis is conducted on returns on equity market indices. Evidence suggests that the degree of integration between the new EU member states and with Germany, which we choose as benchmark for the euro area, has increased in their process towards EU accession. A more refined investigation, however, indicates that most of the observed increase in integration was driven by the three new EU member states with the largest economies and most developed financial markets, Czech Republic, Hungary and Poland. For the four smaller countries, Cyprus, Estonia, Latvia and Slovenia, we find that the degree of integration between themselves and with Germany was close to zero during the mid 1990's and remains low and/or unchanged afterwards. Institutional factors, the sheer size of the economy, geographical distance and weak economic linkages with Germany could be responsible for these results. Although all the considered countries have experienced tremendous development in their stock markets, their degrees of integration and speed of convergence with the euro-zone differ quite markedly. 


\section{References}

[1] Adler, M. and B. Dumas, 1983, "International Portfolio Choice and Corporation Finance: A Synthesis," Journal of Finance 38(3): 925-984.

[2] Aydemir, A.C., 2004, "Why are International Equity Market Correlations Low?," Unpublished working paper, Carnegie Mellon University.

[3] Baele, L., A. Ferrando, P. Hördahl, E. Krylova, and C. Monnet, 2004, "Measuring Financial Integration in the Euro Area," ECB OP \# 14.

[4] Bekaert, G., 1999, "Is There a Free Lunch in Emerging Market Equities?," Journal of Portfolio Management 25(3): 83-95.

[5] Bekaert, G., C.B. Erb, C.R. Harvey and T.E. Viskanta, 1998, "Distributional Characteristics of Emerging Market Returns and Asset Allocation," Journal of Portfolio Management 24(2): 102-116.

[6] Bekaert, G. and C.R. Harvey, 1995, "Time-Varying World Market Integration," Journal of Finance 50(2): 403-444.

[7] Bekaert, G. and C.R. Harvey, 1997, "Emerging Equity Market Volatility," Journal of Financial Economics 43(1): 29-77.

[8] Bekaert, G. and C.R. Harvey, 2000, "Foreign Speculators and Emerging Equity Markets," Journal of Finance 55(2): 565-613.

[9] Bekaert, G. and M.C. Urias, 1996, "Diversification, Integration and Emerging Market Closed-End Funds," Journal of Finance 51(3): 835-869.

[10] Campbell, J.Y. and Y. Hamao, 1992, "Predictable Stock Returns in the United States and Japan: A Study of Long-Term Capital Market Integration," Journal of Finance 47(1): 43-70.

[11] Cappiello, L., B. Gérard, and S. Manganelli, 2005, "Measuring Comovements by Regression Quantiles," ECB WP Series \# 501.

[12] Carrieri, F., V. Errunza and S. Sarkissian, 2004, "Industry Risk and Market Integration," Management Science 50(2): 207-221. 
[13] Caviglia, G., G. Krause, and C. Thimann, 2002, Key Features of the Financial Sectors in EU Accession Countries, in C. Thimann (ed.), Financial Sectors in EU Accession Countries, European Central Bank.

[14] Dumas, B., C.R. Harvey and P. Ruiz, 2003, "Are Correlations of Stock Returns Justified by Subsequent Changes in National Outputs?," Journal of International Money and Finance, 22(6): 777-811.

[15] Engle, R.F. and S. Manganelli, 2004, "CAViaR: Conditional Autoregressive Value at Risk by Regression Quantiles," Journal of Business 83 Economic Statistics 22(4): 367-381.

[16] Flood, R.P. and A.K. Rose, 2005, "Estimating the Expected Marginal Rate of Substitution: A Systematic Exploitation of Idiosyncratic Risk," Journal of Monetary Economics 52(5): 951-969.

[17] Forbes, K.J. and R. Rigobon, 2002, "No Contagion, Only Interdependence: Measuring Stock Market Comovements," Journal of Finance 57(5): 2223-2261.

[18] Gérard, B., K. Thanyalakpark and J. Batten, 2003, "Are East Asian Markets Integrated? Evidence from the ICAPM," Journal of Economics and Business, 55(6): 585-607.

[19] Jorion, P. and E. Schwartz, 1986, "Integration vs. Segmentation in the Canadian Stock Market,". Journal of Finance 41(3): 603-613.

[20] Korajczyk, R. A. and C. J. Viallet, 1989, "An Empirical Investigation of International Asset Pricing," Review of Financial Studies 2(4): 553-586.

[21] Rockinger, M. and G. Urga, 2001, "A Time-Varying Parameter Model to Test for Predictability and Integration in the Stock Markets of Transition Economies," Journal of Business and Economic Statistics 19(1): 73-84.

[22] Stulz, R. M., 1981, "A Model of International Asset Pricing," Journal of Financial Economics, 9(4): 383-406. 


\section{Figure 1: The comovement box}

Figure 1 plots the probability that an asset return $r_{i t}$ falls below (above) its $\theta$-quantile conditional on another asset return $r_{j t}$ being below (above) its $\theta$-quantile, for $\theta<0.5(\theta \geq 0.5)$. The case of perfect positive correlation (co-monotonicity), independence, and perfect negative correlation (counter-monotonicity) are represented.

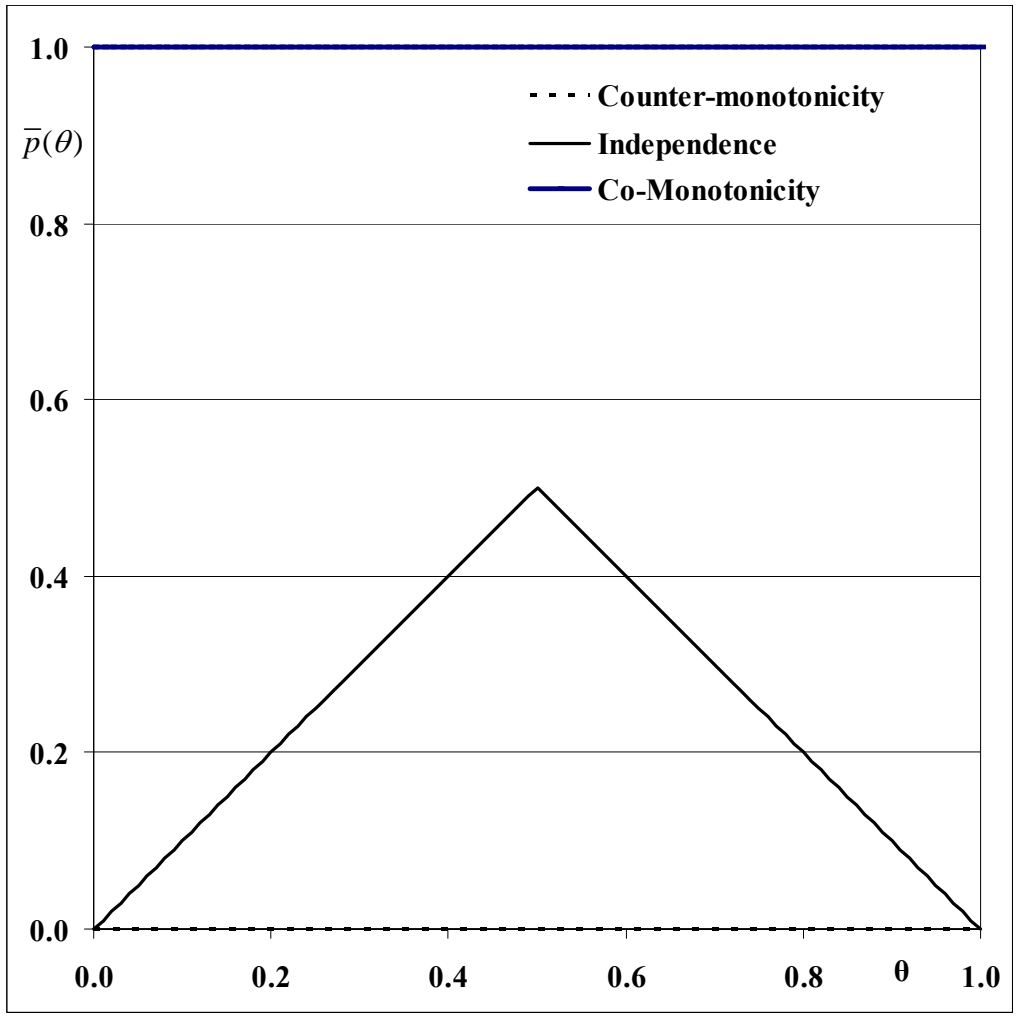


Figure 2: Weighted average conditional probabilities of comovements between returns on new EU member states and Germany equity market indices over the pre- and the post-convergence periods

Figures 2a-2c plot weighted average estimated conditional probabilities of comovements between returns on new EU member states and Germany equity market indices over two periods. The first sub-sample covers the pre-convergence period (January 1993 to August 1998), while the second the convergence period (January 2001 to November 2004). The probability of comovement of each new EU member state vis-à-vis Germany is weighted by the fraction of its GDP relative to the total new EU member state GDP.

Figure 2a: Germany vs. new EU member states

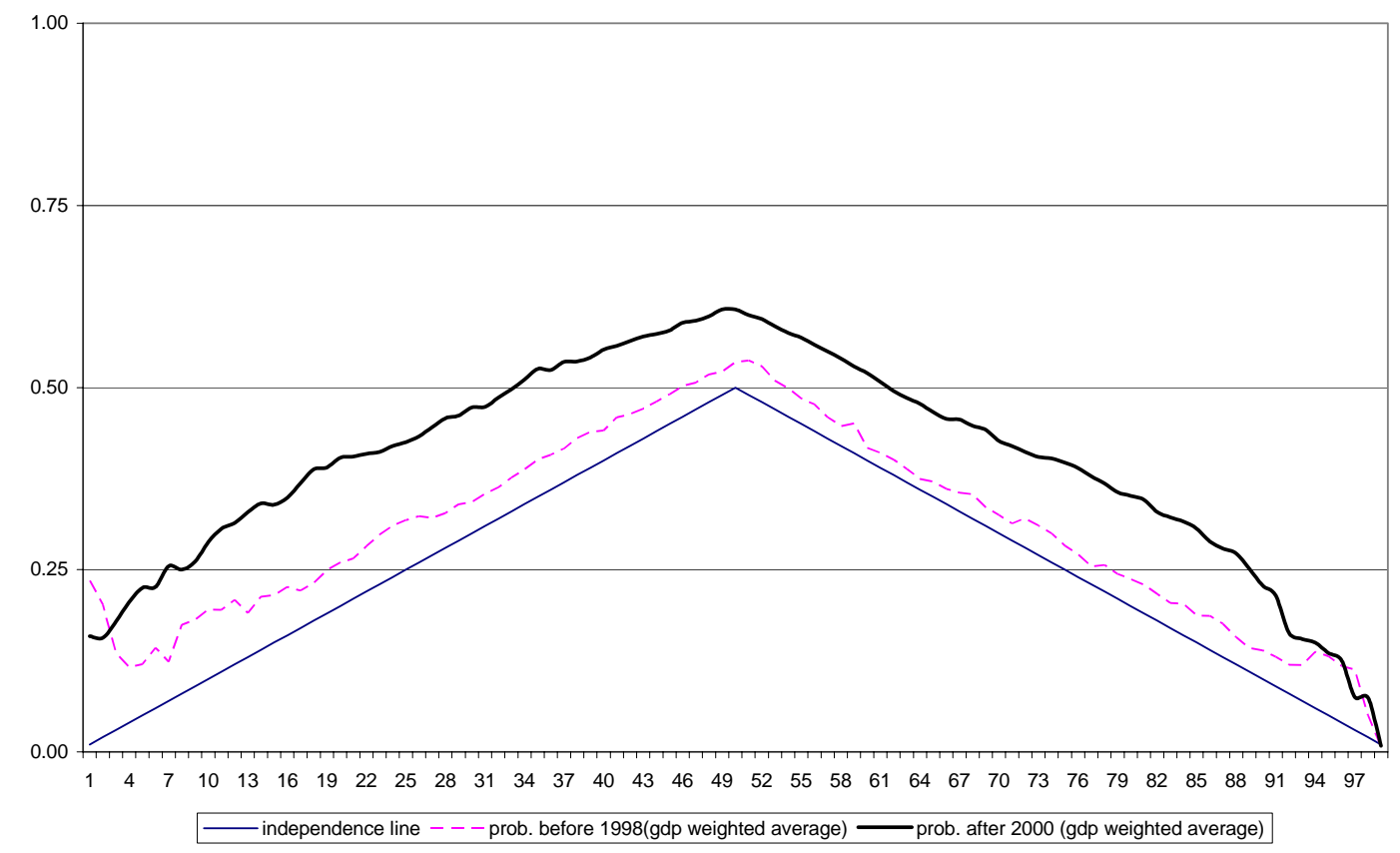




\section{Figure 2 - Continued}

Figure 2b: Germany vs. large new EU member states (Czech Republic, Hungary, and Poland)

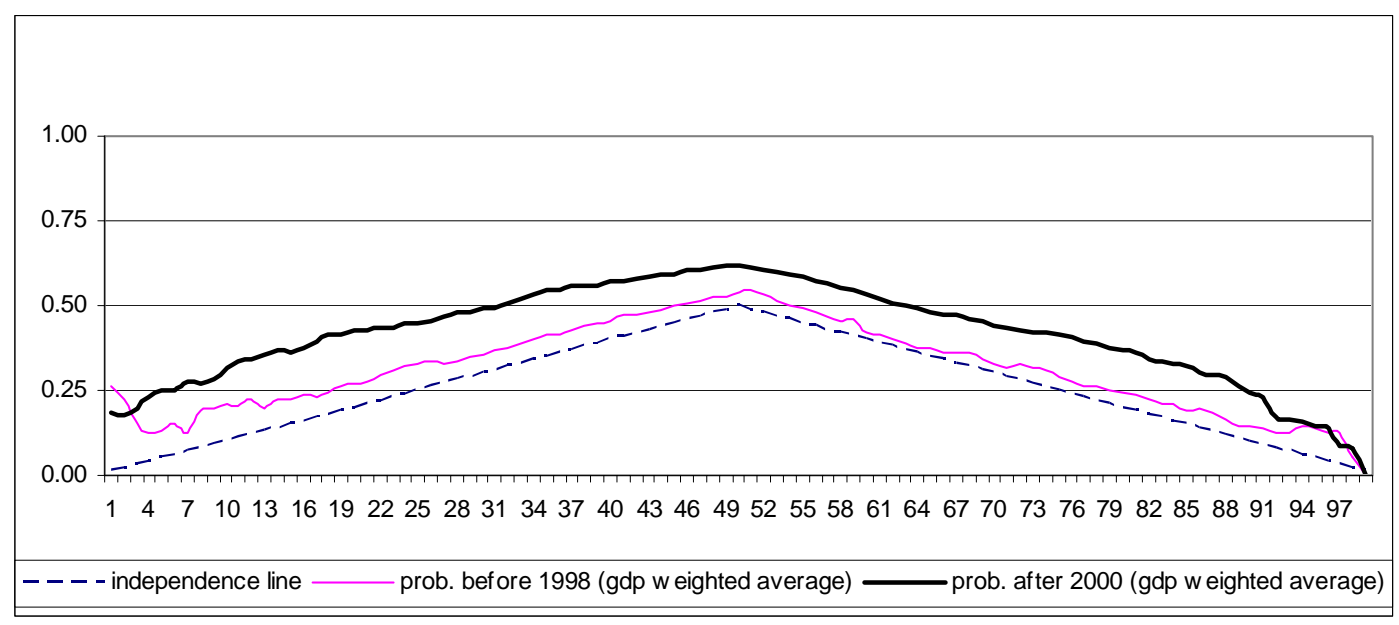

Figure 2c: Germany vs. small new EU member states (Cyprus, Estonia, Latvia, and Slovenia)

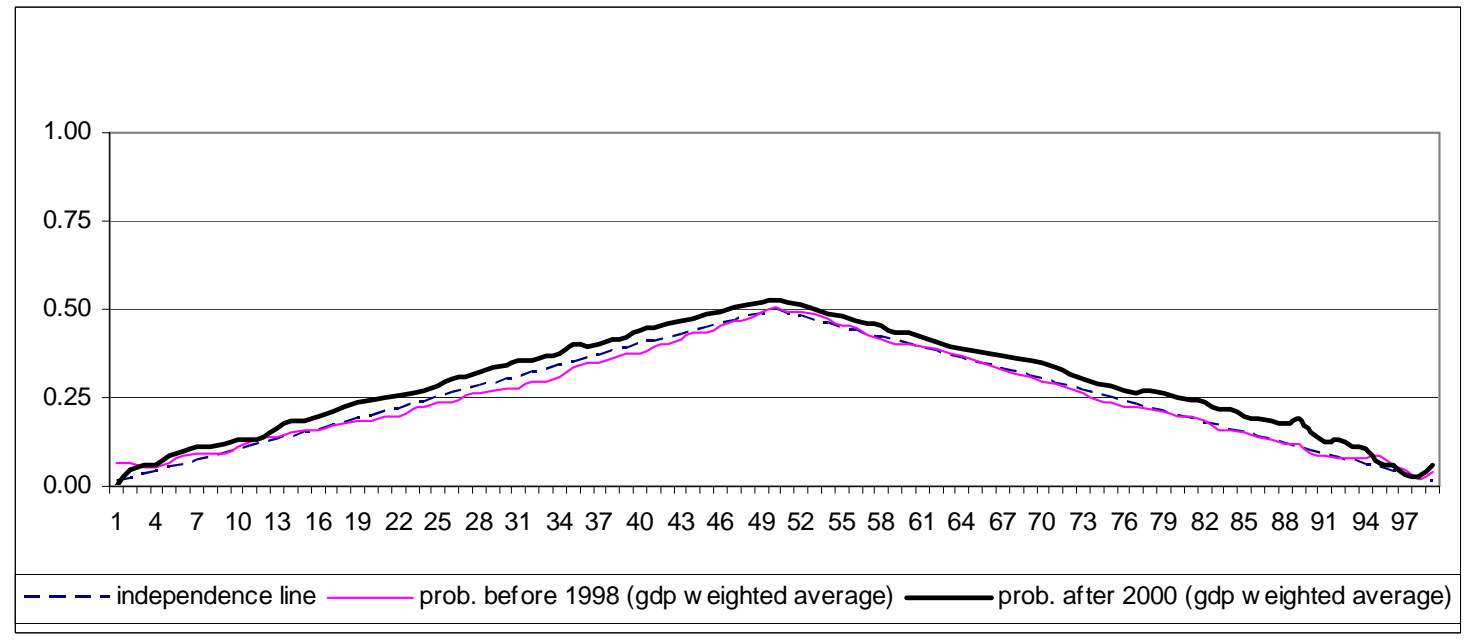




\section{Figure 3: Conditional probabilities of comovements between returns on Czech}

Republic and Germany equity market indices over the pre- and the postconvergence periods

Figures 3 plots the estimated conditional probabilities of comovements between returns on Czech Republic and Germany equity market indices over two periods. The first sub-sample covers the pre-convergence period (January 1993 to August 1998), while the second the convergence period (January 2001 to November 2004). The dashed lines denote the two standard error bounds around the estimated comovement likelihood in the convergence period.

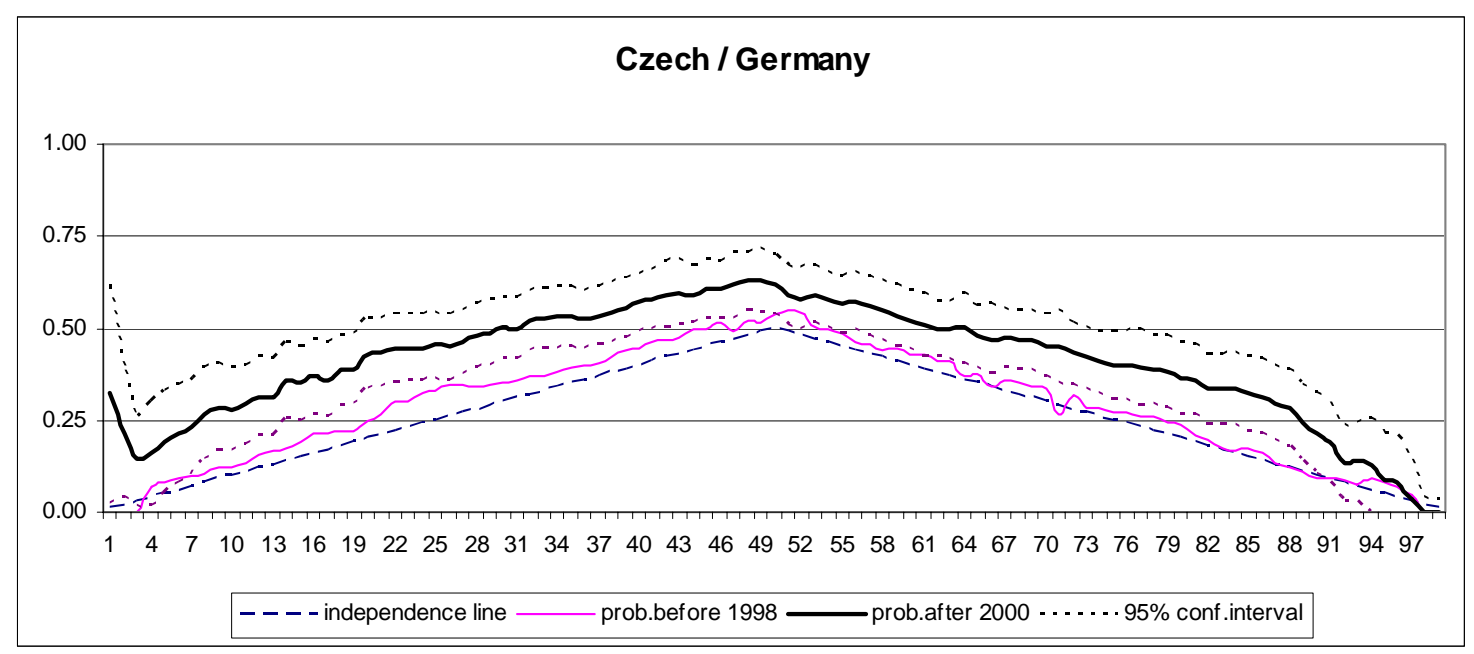


Figure 4: Weighted average conditional probabilities of comovements between returns on new EU member states equity market indices over the preand post-convergence periods

Figures 4a-4c plot weighted average estimated conditional probabilities of comovements between returns on new EU member states equity market indices over two periods. The first sub-sample covers the pre-convergence period (January 1993 to August 1998), while the second the convergence period (January 2001 to November 2004). The probability of comovement between each country pair is weighted by the fraction of that GDP country pair relative to the sum of all possible country pair GDP.

Figure 4a: New EU member states

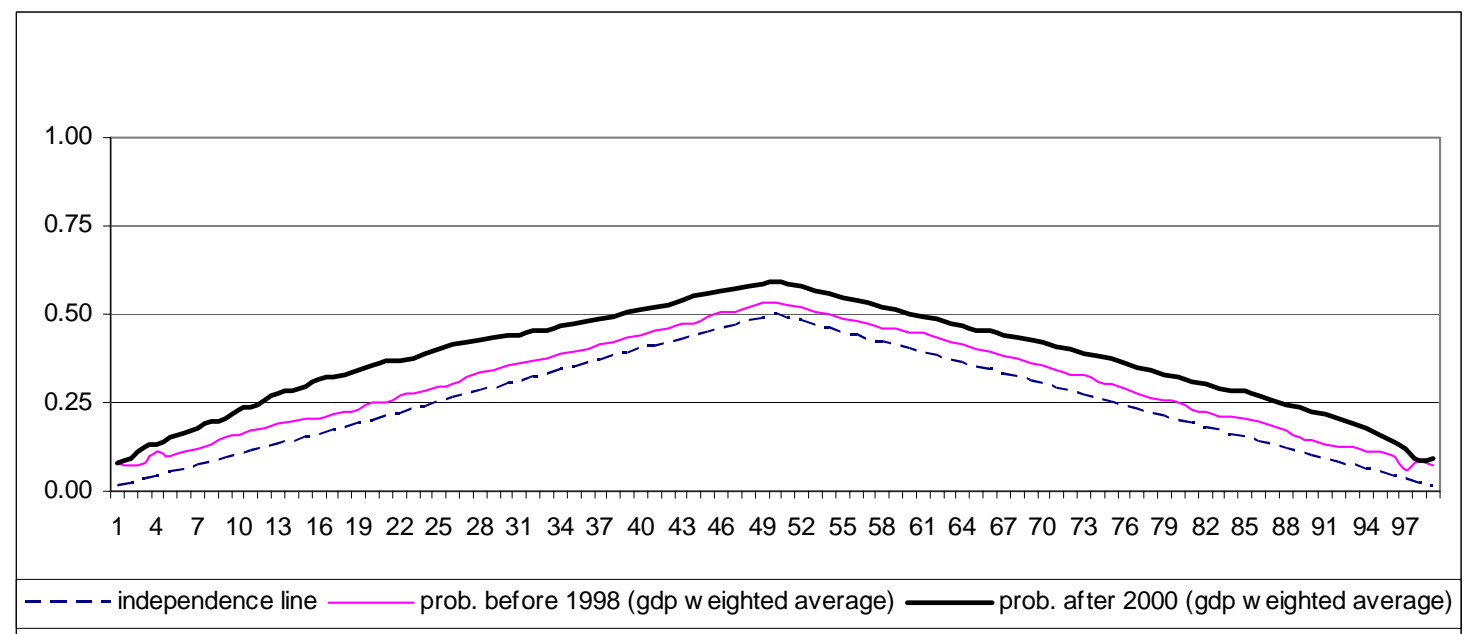




\section{Figure 4 - Continued}

Figure 4b: Large new EU member states (Czech Republic, Hungary, and Poland)

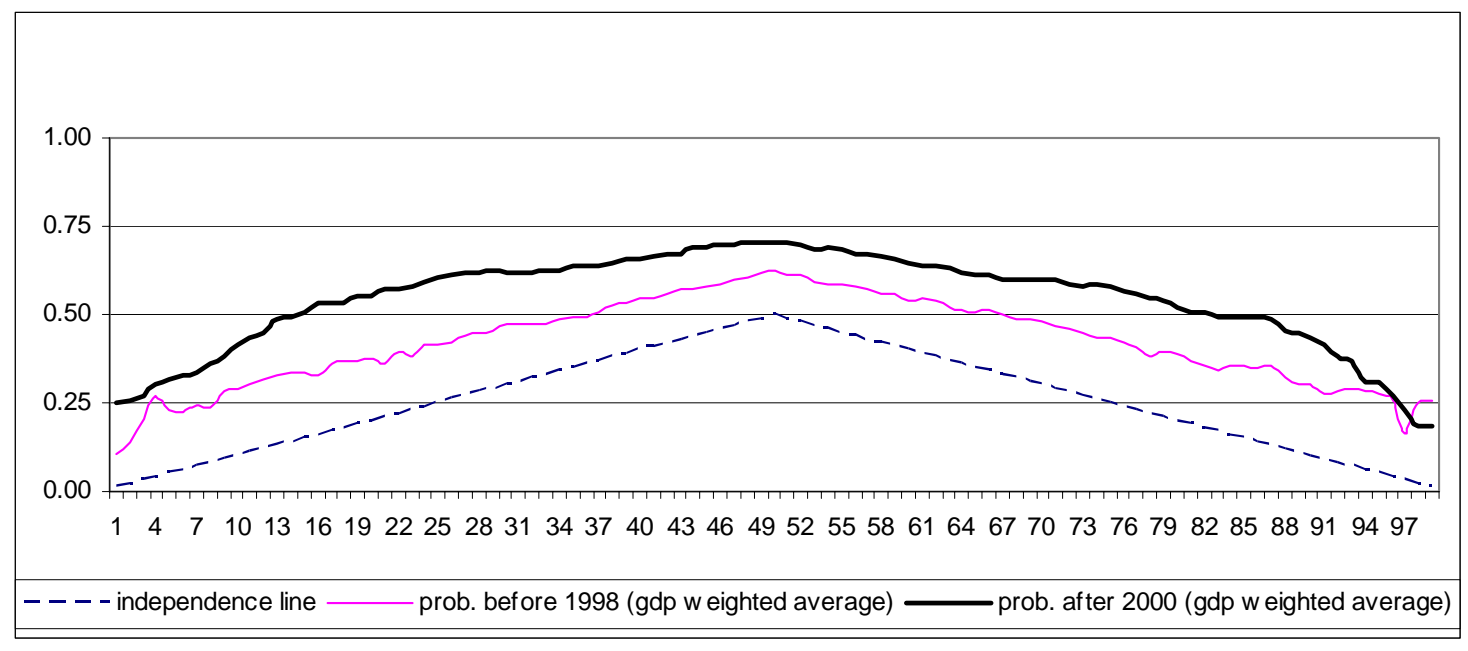

Figure 4c: Small new EU member states (Cyprus, Estonia, Latvia, and Slovenia)

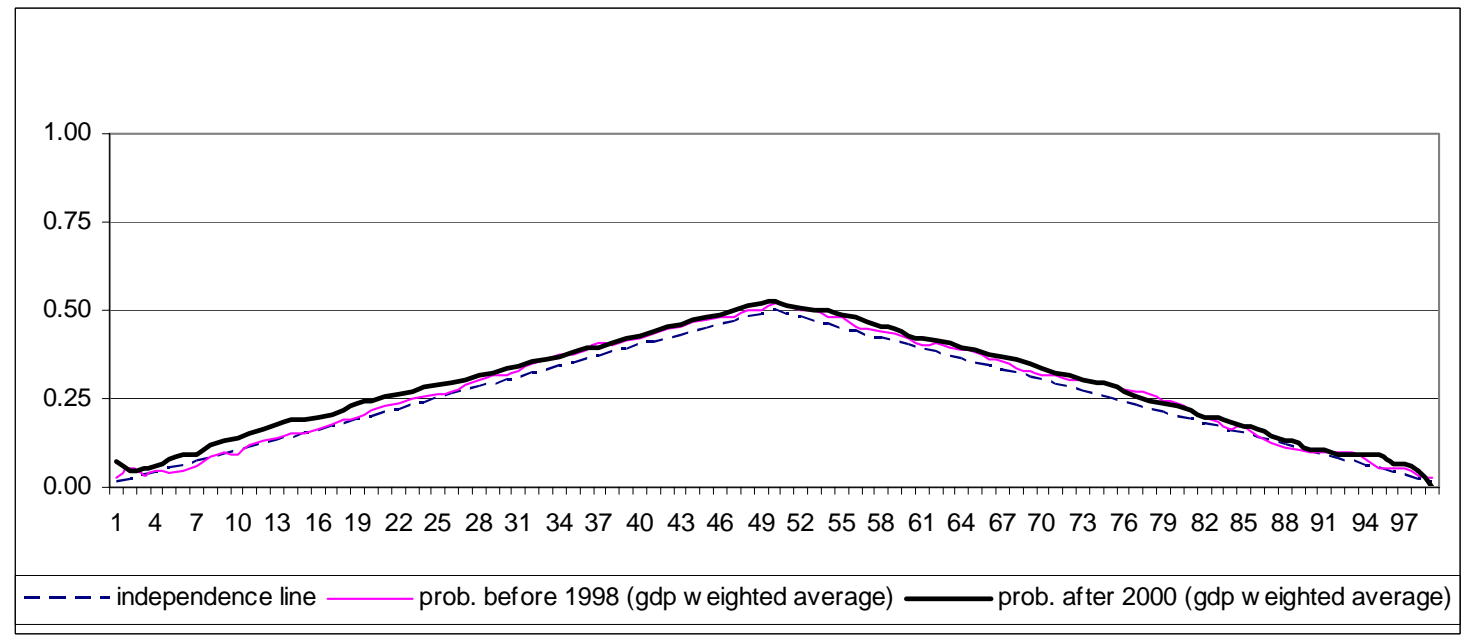


Figure 5: Conditional probabilities of comovements between returns on Hungarian and Polish equity market indices over the pre- and the postconvergence periods

Figures 5 plots the estimated conditional probabilities of comovements between returns on Hungarian and Polish equity market indices over two periods. The first sub-sample covers the preconvergence period (January 1993 to August 1998), while the second the convergence period (January 2001 to November 2004). The dashed lines denote the two standard error bounds around the estimated comovement likelihood in the convergence period.

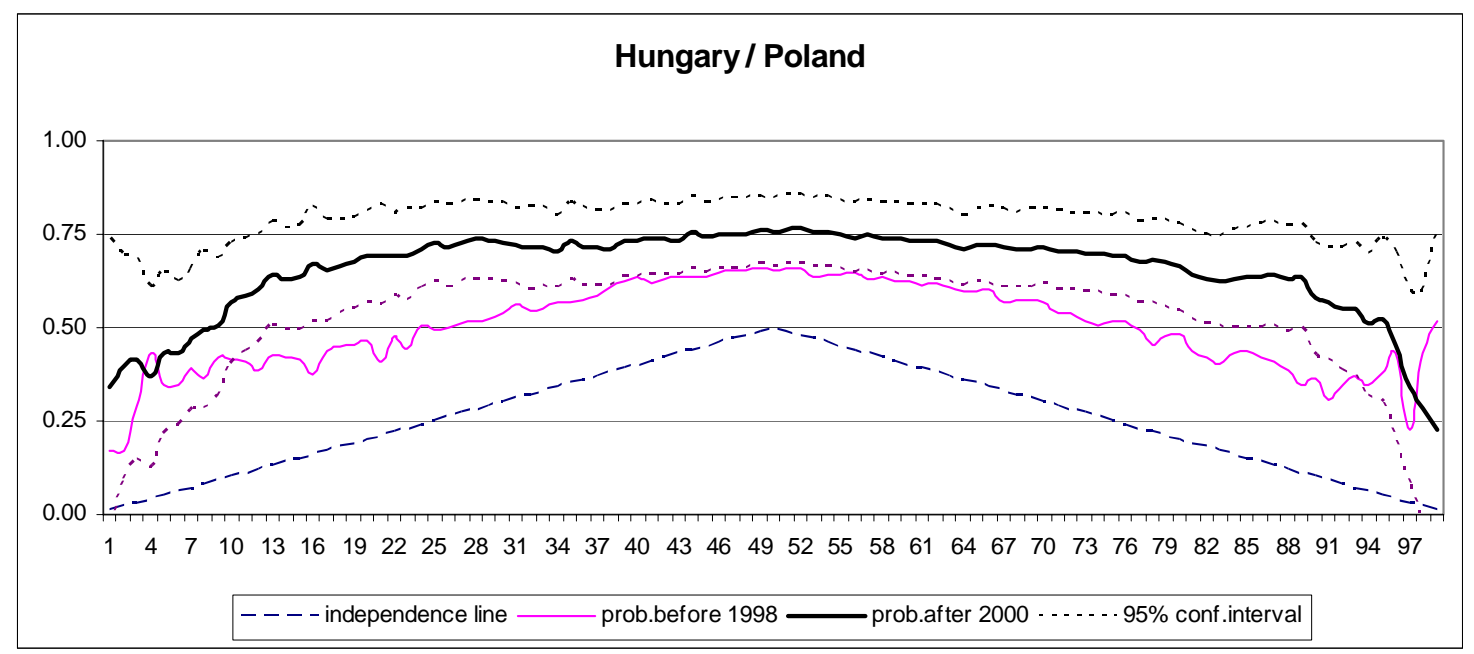

